\title{
Biologically inspired design for environment
}

\author{
Lenau, Torben A.; Pigosso, Daniela C. A. ; McAloone, Tim C.; Lakhtakia, Akhlesh
}

Published in:

Bioinspiration, Biomimetics, and Bioreplication X

Link to article, DOI:

$10.1117 / 12.2558498$

Publication date:

2020

Document Version

Publisher's PDF, also known as Version of record

Link back to DTU Orbit

Citation $(A P A)$ :

Lenau, T. A., Pigosso, D. C. A., McAloone, T. C., \& Lakhtakia, A. (2020). Biologically inspired design for environment. In M. Knez, A. Lakhtakia, \& R. J. Martín-Palma (Eds.), Bioinspiration, Biomimetics, and Bioreplication X [113740E] SPIE - International Society for Optical Engineering. Proceedings of SPIE - The International Society for Optical Engineering Vol. 11374 https://doi.org/10.1117/12.2558498

\section{General rights}

Copyright and moral rights for the publications made accessible in the public portal are retained by the authors and/or other copyright owners and it is a condition of accessing publications that users recognise and abide by the legal requirements associated with these rights.

- Users may download and print one copy of any publication from the public portal for the purpose of private study or research.

- You may not further distribute the material or use it for any profit-making activity or commercial gain

- You may freely distribute the URL identifying the publication in the public portal 


\section{Biologically inspired design for environment}

Lenau, Torben, Pigosso, Daniela C., McAloone, Tim, Lakhtakia, Akhlesh

Torben A. Lenau, Daniela C. A. Pigosso, Tim C. McAloone, Akhlesh Lakhtakia, "Biologically inspired design for environment," Proc. SPIE 11374, Bioinspiration, Biomimetics, and Bioreplication X, 113740E (22 April 2020); doi: $10.1117 / 12.2558498$

SPIE. Event: SPIE Smart Structures + Nondestructive Evaluation, 2020, Online Only 


\title{
Biologically Inspired Design for Environment
}

\author{
Torben A. Lenau**a , Daniela C.A. Pigosso ${ }^{a}$, Tim C. McAloone ${ }^{a}$, and Akhlesh Lakhtakia ${ }^{b}$ \\ ${ }^{a}$ Department of Mechanical Engineering, Technical University of Denmark, DK2800 Kgs. Lyngby, \\ Denmark; ${ }^{b}$ Department of Engineering Science and Mechanics, Pennsylvania State University, \\ University Park, PA 16802, USA
}

\begin{abstract}
Design for Environment (DfE or ecodesign) aims at developing products with an enhanced environmental performance, without compromising functionality and other key requirements (such as cost and quality). Common DfE guidelines for product design include: reduction of material diversity, extension of useful life (e.g., by enabling repair and upgrade), avoidance of toxic materials and nonrenewable resources, use of recycled components, and ease of disassembly and recyclability after the end of useful life. DfE requires the integration of environmental considerations into the traditional design processes, supporting decisions that could enhance the environmental profile of the product. Biologicallyinspired-design (BID) teams identify and isolate the core principles of relevance for systems, products, and processes from the bioworld for consideration and possible incorporation during each of the design stages. Synergies and potential trade-offs existing between DfE and BID must be considered when integrating the two methodologies into Biologically Inspired Design for Environment for the design of products and systems.
\end{abstract}

Keywords: Biomimetics, design, engineered biomimicry, environment, sustainability

\section{INTRODUCTION}

Concern about sustainable development is mounting as resource consumption and pollution levels on our planet increase. In 1987, the Brundtland Commission of the United Nations ${ }^{1,2}$ defined sustainable development as "development that meets the needs of the present without compromising the ability of future generations to meet their own needs." The Commission considered three areas of concern for sustainable development: (i) environment, (ii) social organization, and (iii) economy. Technological development as well the global connectedness of human society currently require the imposition of serious curbs on consumption, especially considering the limited availability of resources (both renewable and non-renewable) and the limited ability of the biosphere to absorb wastes excreted by human activities. However, both technological development and social organization can be managed and improved to make way for enhanced economic growth and global equality. Sustainable development requires lifestyles that are consistent with the planet's ecological boundaries, for instance, in their use of raw materials and energy. Also, population increase needs to be in harmony with the changing productive potential of the ecosystem.

The quest for sustainable development was taken further in the 2030 Agenda for Sustainable Development which, in 2015, resulted in the United Nations General Assembly adopting 17 Sustainable Development Goals (SDGs). ${ }^{3}$ The SDGs are operational goals focused on concrete actions. All 17 can be considered as relevant to the previously mentioned three areas of concern: the environment (also referred to as the biosphere), social organization, and economy. ${ }^{4}$ It is worth noting that SDG\#12 (Responsible Consumption and Production) is a challenge for most countries - and especially the developed countries (Fig. 1). The development, manufacture, and post-use disposal of products are at the heart of most of the unsustainable activities - from the environmental, social and economic perspectives. ${ }^{5}$

In order to enable the growing world population to exist with a desirable living standard for all without seriously impairing the biological environment, it is imperative that we carefully design our societies and ways of living so that energy generation and resource consumption are sustainable. This is what Design for Environment (DfE) or ecodesign is about. DfE integrates environmental considerations across all design activities, including: analyses of a problem, creation of conceptual solutions, embodiment of those concepts, and detailed design. The integration of environmental considerations right from the early design phases helps develop products with a lower environmental impact across the life cycle (from raw material extraction and manufacturing, to use and end-of-use/end-of-life).

\footnotetext{
Bioinspiration, Biomimetics, and Bioreplication X, edited by Mato Knez, Akhlesh Lakhtakia, Raúl J. Martín-Palma,
} Proc. of SPIE Vol. 11374, 113740E · (c) 2020 SPIE · CCC code: 0277-786X/20/\$21 - doi: 10.1117/12.2558498 
Different DfE approaches, methods, and tools can help to complete the different activities in an effective and efficient way. Biological inspiration is an approach to stimulate searches for good solutions and the bioworld may even provide detailed instructions for implementing some of those solutions.

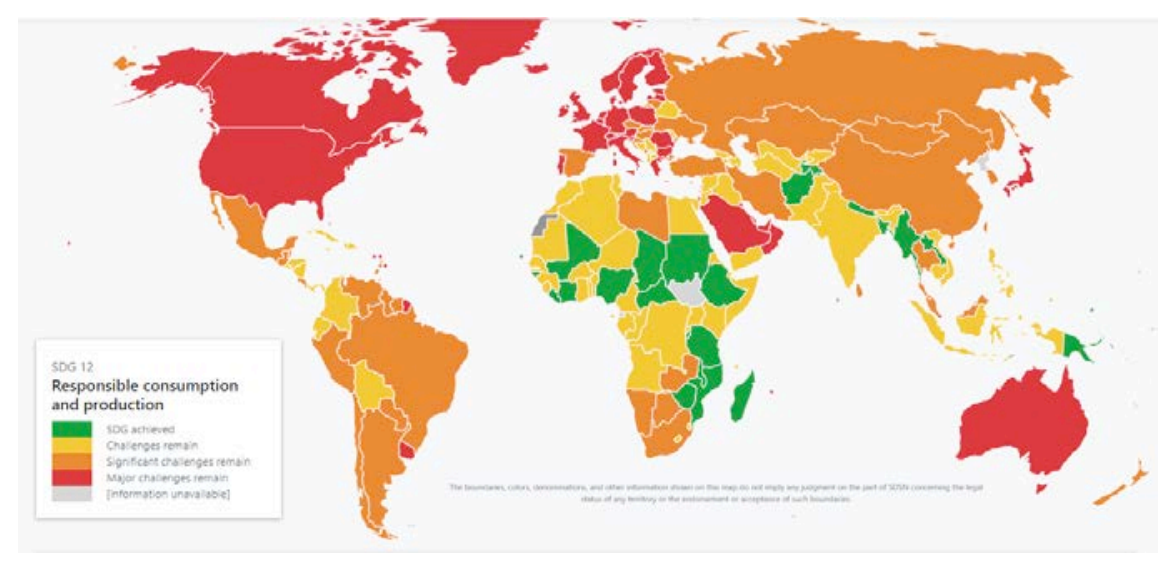

Figure 1: Global status of SDG\#12. ${ }^{6}$

Biologically Inspired Design (BID) can be used to address and propose actions within all three areas of concern for sustainable development, with a special focus in using inspiration from the bioworld to solve problems relating to the biosphere. The following SDGs can be impacted by BID:

- SDG 6: clean water and sanitation,

- $\quad$ SDG 7: affordable and clean energy,

- SDG 13: climate action,

- $\quad$ SDG 14: life below water, and

- $\quad$ SDG 15: life on land.

Both economy and social organization are human constructs and, even though inspirations for their improvement can be found in the bioworld, the dominant application of BID is for technological solutions in line with SDGs 6, 7, 13, 14, and 15. The bioworld presents many approaches that can be adapted for circular economy, resource efficiency, and ecosystem balances.

There are numerous examples of natural systems in balance where many different organisms coexist and often benefit from symbiotic relations. Well known are the forest ecosystems where old trees fall and are degraded by insects and fungi into soil for the benefit of new plants. Also, many organisms showcase impressive examples of strategies for survival in extreme conditions. Polar bears live through the arctic winter without eating for several months. Frogs survive being deep frozen without the formation of destructive ice crystal inside their cells. The bioworld also suggests that resource consumption must be minimum. Ceramic materials with high toughness but formed at room temperatures are found in mollusk shells. In contrast humans need very high temperatures and considerable energy for producing similar materials, for instance, to make ceramic cups and dinner plates. There are many excellent models in nature for organizing circular resilient systems and optimizing for resource efficiency.

However, the bioworld is not always a good model that complies with the ethical standards of human beings, and emulating it may actually be undesirable from environmental considerations. For instance, will the burned-soil strategy commonplace in American redwood forests be acceptable as a model for control of agricultural pests? Similarly, will the predator-prey relationship be desirable as a model for population control? The bioworld also exhibits unacceptable fluctuations such as the great grasshopper swarms that destroy large agricultural fields in Africa at regular intervals.

Another limitation in BID is the complexity in the bioworld. Many natural phenomena appear simple at first glance, but careful studies clarify the many intricate mechanisms assuring a desirable effect. Also, biochemical mechanisms underlie 
many biological processes, which makes it hard for designers and many engineers to understand those processes without proper training.

\section{DESIGN PROCESSES}

\subsection{Design process phases}

New and improved products are developed in a design process. Design activities take place when artifacts and systems need to change. The design object can be either a single product or a system involving several products that interact and impact the functionalities and performances of each other. The principal design processes are the same for all design objects.

The design of a product or system typically involves four phases in the following sequence: ${ }^{7}$

- definition and clarification of the need for the product or system;

- conceptualization of the product or system and the production/realization process;

- preparation of its embodiment to focus the attentions of all stakeholders; and

- creation of the necessary detail for production and realization.

The following example illustrates the activities within the four design phases. Suppose that a new type of electric vehicle suitable for transportation over short distances is being developed. In the first design phase, the opportunities for different target user groups have to be analyzed. The targeted users may be young individuals, families with children, and/or senior citizens. Apart from the specifications for the specific vehicle there will be context and system investigations: Where and how the vehicle should be charged and different types of ownership or rental models must be evaluated. Solutions must be compared with competing solutions such as cars, bicycles, buses, subway trains, and trams. Conceptualization activities encompass the envelope considerations such as whether the vehicle should include a cabin for protection against inclement weather or if it should be open like a scooter. At the embodiment phase, specifics about how to shape and layout the product must be decided and could include consideration on the number of wheels and the placement of the motor in the vehicle. Finally, in the detailed design phase, the concrete dimensions have to be decided and a detailed material-selection process must be undertaken.

\section{DESIGN FOR ENVIRONMENT}

DfE aims for integrating environmental considerations into the early stages of the product development process, because about $80 \%$ of the environmental impacts of a product can be defined in the early design phases. ${ }^{8}$ At the same time as enhancing the overall environmental performance of a product, it is important not to compromise other key traditional requirements (such as cost, quality, and aesthetics) so as to ensure that the products are competitive in the market and can actually replace less environmentally sustainable products. ${ }^{9}$

\subsection{Problem definition phase}

Hotspots for impact minimization across lifecycle phases are identified in the problem-definition phase of DfE, i.e., the environmental hotspots to be approached are determined (both in terms of lifecycle stages and environmental aspects). Several tools are available for the quantification of the environmental hotspots across the product life cycle, including qualitative, semi-quantitative and quantitative tools (such as Life Cycle Assessment).

One example of a semi-quantitative (or screening tool) is the MECO matrix ${ }^{10}$ whereby the use of materials, energy, chemicals, and other resources is delineated for each life-cycle phase (i.e. materials, manufacture, transport, use, and disposal. An example of the MECO matrix is shown in Fig. 2. On the basis of the collected data for each one of the cells for a reference product (which can be an existing product or a competitor's product), it is possible to identify the key hotspots that will drive product development. 


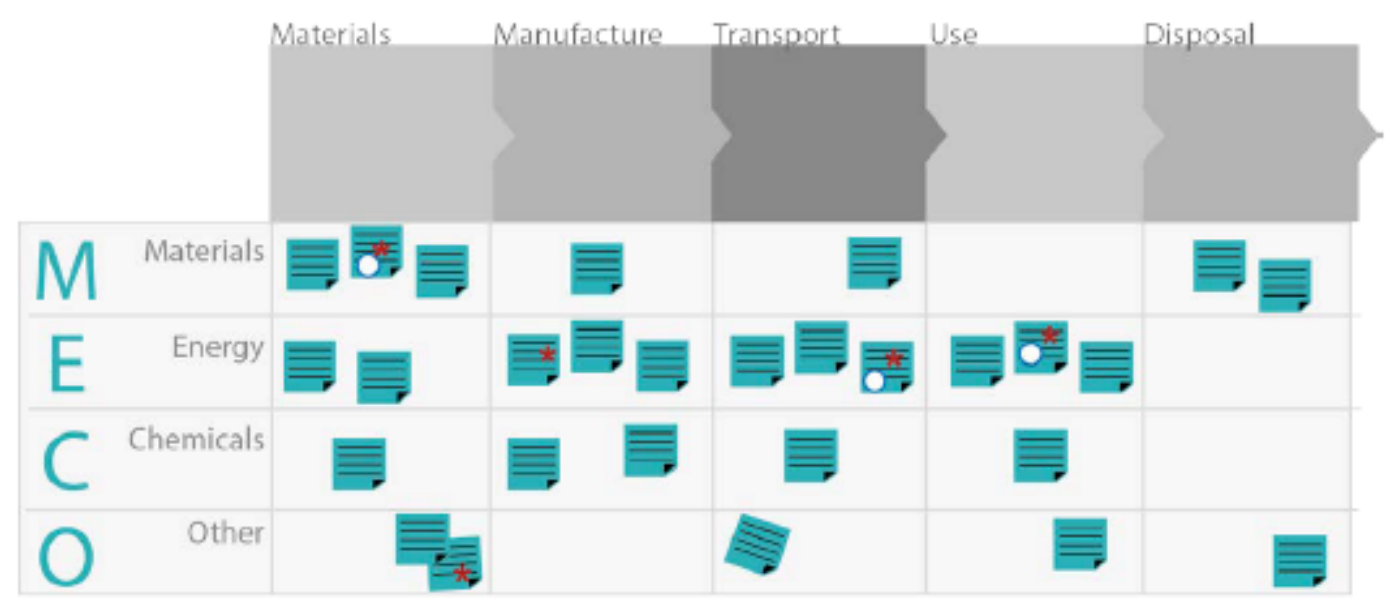

Figure 2. The MECO matrix for identification of environmental hotspots.

Mapping of the applicable ecodesign-related legal issues and standards is also a key activity at this stage. Over the past few years, there has been an exponential growth in the volume and coverage of legislation dealing with the environmental performance of products across the entire life cycle. ${ }^{11}$ Understanding the competitive landscape is also key for the task clarification - and can be carried out by analyzing competitor products in the market, by mean of ecobenchmarking studies. ${ }^{12}$

\subsection{Conceptualization phase}

Most opportunities for DfE implementation rely on the conceptualization phase, with the definition of the key characteristics of the product that will influence the environmental performance of the product across the entire life cycle. The next activity in the design process is related to the function analysis, which brings the opportunity to find new ways to deliver functions to the user with enhanced environmental performance. Several different product concepts are then developed in order to achieve the required solution (on the basis of lists of product specifications and requirements). In order to support this process, several DfE strategies can be implemented using guidelines and design options such as ${ }^{13}$ :

- reduction of material diversity. In our quest for high-performance products, the numbers of materials used in many products have risen sharply. For example, 600 different plastic materials are used in electronic products. ${ }^{14}$ This high number severely limits post-use recycling of materials, the logistics becomes complicated, and the identification as well as the correct processing of diverse materials also becomes an overwhelming challenge.

- extension of useful life (e.g., by enabling repair and upgrade). Traditional business models encourage shorter product-use cycles, which puts pressures on resource availability as well as waste-handling systems. Several guidelines are available for the development of products that can be upgraded, repaired, reused, refurbished, remanufactured, and repurposed (which has become increasingly important in a circular economy). ${ }^{15}$ By implementing these guidelines, the useful life of a product can be significantly extended, which enables the delivery of the function with a minimized resource use. Furthermore, the adoption of product-service-system business models, which implies changes in the product ownership structure from the user to the provider, change the basic incentives and encourage longer product-use cycles, reparability, and recycling. ${ }^{16}$

- use of recyclable and recycled components. Many products today are not designed with end-of-life scenarios in mind. The consequence is that the recycling of products is difficult, both technologically and economically. Several strategies exist to enable the design for recycling, cascading, and energy recovery. ${ }^{15}$ While recycling and cascading enable an extension of the material lifetime, energy recovery (e.g., for heating) facilitates circular economy. It is important to remember that the extension of the product lifetime is often preferred to the extension of the material lifetime, as most of the manufacturing value aggregated is retained.

- maintenance of a healthy environment. Many toxic and hazardous materials are still used for the manufacturing and operation of products, causing serious damage to the environment and biosphere when released (e.g. through contamination of air, water and soil). Laws exist to control the use of those toxic substances (e.g. 
$\mathrm{REACH}^{17}$ and $\mathrm{RoHS}^{18}$ ). Hence, available alternative materials and chemicals with similar mechanical, thermal, and chemical properties should be considered during the design process.

- reduce the use of nonrenewable resources. Use of renewable materials and energy sources is preferable to the use of non-renewable materials, because the latter increases the environmental pressure both in terms of scarcity and carbon footprint. It is important to remember, however, that renewable materials are not always better from an environmental perspective, and a detailed analysis should be carried out before their adoption.

With the alternative concepts created, the last activity of the conceptualization phase is related to the evaluation and prioritisation of the concept to be further developed in the next phase, embodiment design. Among the many tools that can support the designer in this task is the ecoconcept spiderweb. ${ }^{19}$

\subsection{Embodiment phase}

Embodiment design is the phase in which the selected concept is further developed into a design that can lead directly to production. By this time, the design of the product is defined to a level in which it is possible to start quantifying its environmental performance, by using more robust, quantitative, and comprehensive tools. One of the most well-known and applied tools for the quantification of the product environmental performance is Life Cycle Assessment (LCA). Life Cycle Assessment aims to evaluate the environmental burdens associated with a product, process, or activity by identifying energy and materials used and wastes released to the environment, and to evaluate and implement opportunities to affect environmental improvements. Simplified LCA, also known as Streamlined LCA, has recently emerged as a quick and efficient way to evaluate the environmental attributes of a product, process, or service life cycle via a short screening process. LCA has gained broad acceptance in industry as a trustworthy tool to quantify the environmental aspects and potential impacts of the life cycle of products. The LCA methodological framework has matured to a standardized approach, defined by ISO 14040 and ISO 14044 standards $^{20,21}$ that describe the minimum requirements for its correct use and performance.

\subsection{Detail-creation phase}

The last phase in the design process encompasses detailed design, whereby the final product is defined together with its dimensions, materials, and manufacturing processes. A key ecodesign activities to be considered at this point is the identification, qualification, and management of suppliers; in turn, each of those suppliers should consider their environmental performance along with the environmental performance of the products/components/materials that it supplies. Finally, it is also important to communicate the environmental performance of the product as part of the total value proposition.

\section{BIOLOGICALLY INSPIRED DESIGN}

The bioworld provides many examples of environmental sustainability. The notable characteristics of biological organisms include:

- energy efficiency of chemical reactions and materials synthesis,

- multifunctionality whereby a certain organ performs multiple functions, and

- resilience provided by alternative strategies to overcome failures.

The bioworld also has numerous symbiotic systems wherein (i) waste from one organism is food for another and (ii) organisms of two different types have a mutually beneficial relationship, as exemplified by mycorrhizal symbiosis and bee-initiated pollination of plants.

Biologically inspired design is the activity of using inspiration from the bioworld to develop technical solutions and it is also referred to as biomimetics, biomimicry, and bionics. ${ }^{22-25}$ The exact meaning of each term is slightly different. For instance, biomimicry is often used for the integration of BID and DfE.

BID is carried out in two basically different ways: ${ }^{26}$

- problem-driven BID: the starting point is the technoscientific problem for which suitable biological analogies and/or replicates are sought; and 
- solution-driven BID: knowledge of the core principles of a biological product or process motivates the search for suitable technoscientific applications.

BID can be applied to single products (e.g., building materials) and to larger systems (e.g., traffic planning, crowd control, and urban planning). Since environmental concern is the starting point for DfE, problem-driven BID is the more relevant approach for DfE/BID integration.

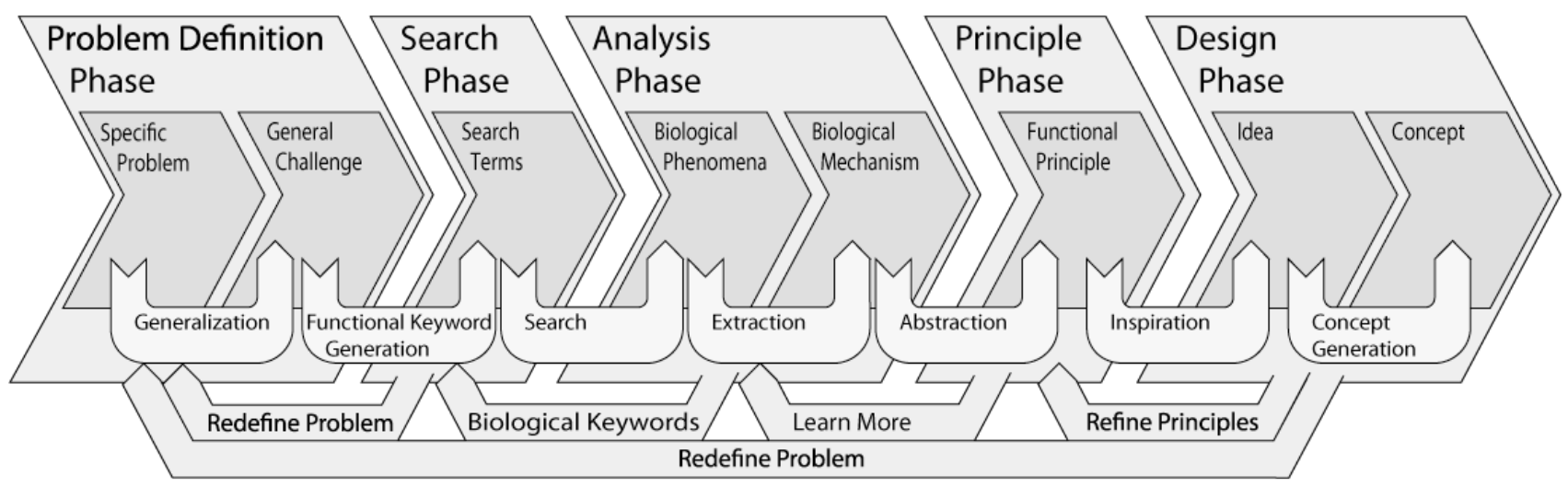

Figure 3. Phases in problem-driven BID.

As described in Fig. 3, problem-driven BID involves four phases before the design phase. The first four phases of BID include: problem definition and understanding, search, analysis, and enunciation of principle(s). Finally, the chosen BID idea is applied in the design phase in a similar way as in traditional design. The design phase involves the inspiration of an idea followed by the generation of a concept that can be applied practically to solve the problem identified in the first BID phase. The phases of problem-driven BID can be incorporated in any one or all of the last three phases of DfE (i.e., conceptualization, embodiment, and detail-creation).

\subsection{BID for the conceptualization phase}

The design phase involves the inspiration of an idea followed by the creative generation of a concept that can be applied practically to solve the problem identified in the first BID phase. Concepts are traditionally generated through brainstorming, but BID requires searches in the bioworld to identify the strategies used in animals and plants to solve similar functional problems. Every search output is analyzed to identify the underlying functional principle, leading to ideation that makes it easier to create conceptual solutions. Thus, a bioworld strategy is extracted and interpreted to extract the functional principle, which is formulated in a way useful to the design process. Biocards are often used to facilitate this translation from biological descriptions into inputs for the conceptual work. ${ }^{27}$

The flow from several ideas to a final concept means that the solution is placed in its context alongside scenarios for specific uses and interfaces with other products and/or systems. For the transportation example, legged motion emulating numerous mammals will have to be ruled out if the terrain were flat and smooth; however, it will have to be considered seriously if the terrain were rugged.

\subsection{BID for embodiment phase}

During the embodiment and detail-creation phases of DfE, a comprehensive description of every viable concept generated by BID is needed. The morphology of the product or system and the arrangement of its constituent elements are determined in embodiment design. For embodiment of legged motion in the transportation example, the numbers of limbs and hinges as well as the placements of actuation and energy-storage elements will have to be decided.

\subsection{BID for detail-creation phase}

The process of creation of detail goes a step further to add specific dimensions and other specifications. An even more detailed understanding of the biologically inspired strategy is needed. For creating details of legged motion in the transportation example, spatial dimensions and weights of all constituent elements will have to be specified. If a kangaroo is chosen as an exemplar, detailing will involve finding equivalent materials for bones, actuators, and energystoring dampers, and determining their dimensions scaled for the actual application. 
Other examples at the product level include: the self-healing nanostructures for polymer wires inspired by the reversible molecular-binding mechanisms in mussel byssus thread that can unsnap and snap, ${ }^{28,29}$ the delicate multilayer construction in Morpho butterfly-wing scales that produce structural colors, ${ }^{30,31}$ and biological pest control using replication of surface features of the elytra of the emerald ash borer. ${ }^{32,33}$

Examples at the system level include: the multi-criteria optimization performed by the slime mold that can help in planning the layout of railroads or motorways, ${ }^{34-36}$ and the democratic decision processes bees demonstrate when looking for new hives. ${ }^{37-39}$

\section{BIOLOGICALLY INSPIRED DESIGN FOR ENVIRONMENT}

The starting point for DfE is the minimization of the overall environmental impacts across the product life cycle, which can be understood as "an environmental problem requiring a solution". The impact can be minimized by redesigning a specific product or the way it is used. To this end, problem-based BID could be an applicable approach. After analyzing the problem, a search is conducted for bioworld processes that overcome issues identified during analysis. Relevant information is extracted about every bioworld process, functional principle(s) are identified, and solutions are proposed during the conceptualization, embodiment and detail-creation phases. All proposed solutions are comparatively assessed to identify the ones with superior potential for environmental sustainability.

Both DfE and BID can be applied at the product level and/or the system level. An example where both methodologies apply at the product level is the texturing of the surfaces of ship hulls that will be submerged in water. The texturing is inspired by sharkskin scales and reduces energy consumption because of drag reduction. ${ }^{40}$ It also imparts anti-fouling characteristics, thereby minimizing marine pollution by toxic paints. An example at the system level is furnished by decentralized traffic control inspired by flocks of birds and schools of fish. ${ }^{41,42}$ More resilient traffic control systems can be realized with a minimum of (energy-consuming) infrastructure, since control is decentralized and taken care of by local traffic units that follow a set of simple rules.

\subsection{Problem-definition phase}

An environmental-sustainability assessment should be made to identify problematic issues needing amelioration (e.g. sustainability hotspots). First, the magnitude and characteristics of a problematic issue are estimated. One approach is to use sustainability screening, which could be done with the MECO matrix. For the transportation example, the MECO matrix will encompass the amounts of different Materials (e.g., steel and rubber) used in a vehicle divided by the lifetime mileage of the vehicle; fuel (i.e., Energy) consumption rate; Chemicals added to the fuel, protective coatings, and decorative coatings; and the environmental consequences of accidents (Other). The functional unit (i.e., the total energy equivalent for transport of a person/kilometer) can be used to compare automobiles with buses and bicycles.

The functional unit is also useful when searching for and comparing with bioworld solutions. For example, the functional unit in the transportation example will lead to an examination of various ways of transport in nature such as walking by humans, running by animals, sliding by slugs, slithering by snakes and earthworms, flying by birds, and swimming by aquatic species. In the problem-definition phase, relevant BID considerations could be what level of solutions that are sought, if the solutions should be at the product level (e.g., diverse vehicles) or the system level (e.g., transportation infrastructure and ridesharing options).

As mentioned earlier, bioworld solutions are not necessarily environmentally sustainable. These solutions can be highly advantageous but, in some cases, can prove harmful because of massive scale-ups necessary for widespread application. Even a very elegant and energy-efficient solution from the bioworld can have undesirable consequences when used repeatedly, just like any other type of technical solution. To evaluate if a solution, whether inspired by the bioworld or not, is desirable, an environmental assessment must be carried out for comparison against alternative solutions. It is also important to take a life-cycle perspective, to avoid burden shifting from one life-cycle stage to the next.

\subsection{Conceptualization phase}

In order to address the identified environmental hotspots, several DfE guidelines can be selected for further exploitation, e.g., to optimize the product lifetime or minimize energy consumption.

At the product level, BID requires a search for biological mechanisms that overcome a similar problematic issue. For example, if energy consumption for marine transport needs to be minimized by drag reduction, the release of air bubbles could be harnessed in emulation of emperor penguin. ${ }^{43}$ The BID idea comprises the air bubbles and their impact on flow 
patterns, but it becomes a concept when specific ways of generating air bubbles and ensuring their correct distribution over a ship hull are planned.

At the system level, conceptualization invokes BID to search for ecosystems where many organisms or individuals interact. For example, the manner of handling human waste can be inspired by the way social insects such as ants organize to carry out the analogous activity of keeping anthills clean. It is not only a question of noticing that individual ants can transport unwanted matter away from the anthill. It is about understanding the division of labor among the various denizens of the anthill, the physical layouts of waste-disposal locations, and the decentralized organization in which every ant knows what to do without supervision by an overall control center. ${ }^{44}$ In other words, it is about understanding the biological system rather than the biological organisms in that system.

Product-level consideration for the transportation example could be on ways to minimize energy consumption by a single vehicle. The high energy efficiency of kangaroo motion could inspire energy recovery when a vehicle is halted. Systemlevel consideration could be on how collaboration among members of a flock of birds improves the energy efficiency of a particular bird in that flock. For instance, drag is lowered when birds are flying in formation or penguins keep warm by moving from the center to the outskirts of the flock.

Finally, every proposed solution must be assessed to determine if it can overcome the specific problematic issue. Furthermore, the environmental performances of alternative solutions can be evaluated to identify potential impacts and benefits, and to support decision-making towards the selection of the most promising concepts from an environmental perspective. Whenever trade-offs are encountered, BID principles can be used to overcome the contradictions and/or come up with alternative concepts.

\subsection{Embodiment phase}

During the embodiment phase, more morphological information will be transferred from the bioworld to engineering. Relevant to the transportation example, this information could include: the muscle-tendon-ligament structure of kangaroo bodies for energy recovery (product level) and the dimensions as well as the shapes assumed by a single bird during flight segments of different types as well as the organization of the flock during flight (system level) and their alignment mechanisms.

In this phase, a detailed environmental assessment of the product (e.g., by using quantitative tools such as LCA) can be carried out to support decision-making regarding material selection, value-chain configuration, etc.

\subsection{Detail-creation phase}

The creation of detail can benefit from BID. For the transportation example, the detailed mechanics and biochemical mechanisms for energy storage and recovery would be needed at the product level, and detailed maps of flying flocks with dimensional information at the system level.

Furthermore, the results of the LCA studies can be used for external communication (e.g., through labelling and certifications), thereby enabling full transparency regarding the environmental performance of the developed product.

\section{DISCUSSION}

DfE and BID are well-established paradigms with developed theoretical methodologies and tools, but presently the two have not been combined in a way for them to be used together efficiently and effectively. Salient issues underlying the integration of DfE and BID into Biologically Inspired Design for Environment (BIDfE) include:

- Getting inspiration from the bioworld for the development of products with enhanced environmental performance. Whenever an environmental hotspot is identified, BID can contribute with biological equivalent solutions that address the same underlying problems. When solution principles are transferred, it can be assessed whether the biological inspired solution has better potential environmental performance.

- Capability of identifying new solution principles capable of addressing the "well-consolidated" DfE guidelines (such as minimize energy consumption or facilitate disassembly). One possible approach could be establishing biological examples for each guideline in order to showcase and motivate for extended use of BID examples for DfE. 
- Disruptive innovations for radical improvements in terms of environmental impact. A compendium of BID examples which illustrate and document the increased performance could stimulate the wider integration of DfE and BID, and lead to the identification of generic design principles.

- Insights from BID for all life-cycle stages (from raw materials and manufacturing to use to end-of-life). Case stories of how BID can contribute to all life-cycle phases also contribute to a wider use of BID for environmental concerns.

- Support from BID for consideration of user behavior during the use phase. BID has typically focused on finding equivalent solutions to functional problems, but the dynamic behavior of animals and plants can also inspire the design and implementation of new and more appropriate behavioral patterns for human beings. An ever-growing compendium of BID examples will pave the way for wider use.

- Comparison of solutions for appropriateness. DfE is compatible with the selection of appropriate solution principles and concepts from a palette of possibilities. As the context and expected-use scenarios known for conceptual solutions, consequences for the market and the environment can be estimated and compared. However, a challenge exists in how to assess and compare solution principles when the context and the expected-use scenario for a product or system is not yet defined. On the other hand, there is a need for criteria to classify and sort solution principles if the palette is large.

- Minimization of the solution space by incorporating DfE constraints. DfE brings additional constraints for the BID process, which may considerably minimize the solution space. On the other hand, a clear environmental goal can facilitate a more focused search and justify the extra work needed to consider both areas.

- Evaluation of new radical solutions from an environmental perspective. This may be difficult not only due to lack of data availability but also because of uncertainty in how radical solutions will affect use patterns and impact the use of associated products.

- Devaluation of BID solutions due to poor environmental performance. As a good BID solution may receive lower priority because of poor environmental performance, careful evaluation of potential trade-offs (e.g., higher functionality vs. inferior environmental performance) must be undertaken.

A strength of BID is that it transfers insights from one discipline into another, but that feature also represents a challenge since it requires that the development arena includes actors from both worlds being able to analyze the environmental challenges and at the same time understand the complexity of the bioworld. The challenge can be addressed by training and educating designers in a multidisciplinary fashion. It can also be addressed by stimulating and training experts from diverse disciplines in efficiently carrying out interdisciplinary development work through collaboration, but that will require overcoming the inertia of already-cast mindsets.

\section{CONCLUDING REMARKS}

Design for Environment has well established theories and tools for addressing the analysis of environmental performance and for proposing better solutions. However, even though asking the right question is half the solution, DfE can benefit from Biologically Inspired Design to create new and often innovative solutions. For the integration of both into

Biologically Inspired Design for Environment, new methods and tools are needed along with successful case stories to illustrate and motivate increased application.

\section{ACKNOWLEDGEMENTS}

A. Lakhtakia thanks the Trustees of The Pennsylvania State University for a sabbatical leave of absence and the Otto Mønsted Foundation for supporting a visiting professorship at the Technical University of Denmark (DTU). He gratefully acknowledges the splendid hospitality of the Section of Engineering Design and Product Development, Department of Mechanical Engineering at DTU. 


\section{REFERENCES}

[1] Richardson, J., Irwin, T., and Sherwin, C., [Design \& Sustainability: A Scoping Report for the Sustainable Design Forum], Design Council, London, United Kingdom (2005).

[2] United Nations, "Report of the World Commission on Environment and Development: Our Common Future A/42/427 Annex - UN Documents: Gathering A Body of Global Agreements," 1987, <http://www.undocuments.net/wced-ocf.htm> (17 November 2019).

[3] United Nations, "Sustainable Development Goals: Sustainable Development Knowledge Platform," 2015, $<$ https://sustainabledevelopment.un.org/?menu=1300> (17 November 2019).

[4] Stockholm Resilience Centre, "How Food Connects All the SDGs," 2019, $<$ https://www.stockholmresilience.org/research/research-news/2016-06-14-how-food-connects-all-thesdgs.html $>$ (17 November 2019).

[5] European Commission, "Green Paper on Integrated Product Policy," 2001, $<$ https://ec.europa.eu/environment/ipp/2001developments.htm> (29 March 2020).

[6] Sachs, J., Schmidt-Traub, G., Kroll, C., Lafortune, G., and Fuller, G., [Sustainable Development Report 2019], Bertelsmann Stiftung and Sustainable Development Solutions Network, New York. NY, USA (2019).

[7] Pahl, G., and Beitz, W., [Engineering Design], Springer, Heidelberg, Germany (1988).

[8] McAloone, T. C., and Bey, N., [Environmental Improvement Through Product Development - A Guide], Danish Environmental Protection Agency, Copenhagen, Denmark (2009).

[9] Luttropp, C., and Lagerstedt, J., "EcoDesign and The Ten Golden Rules: generic advice for merging environmental aspects into product development," Journal of Cleaner Production 14(15-16), 1396-1408 (2006).

[10] Pommer, K., Bech, P., Wenzel, H., Caspersen, N.., Olsen, S. I., [Handbook on Environmental Assessment of Products], Danish Environmental Protection Agency, Copenhagen, Denmark (2003).

[11] Pigosso, D. C. A., Ferraz, M., Teixeira, C. E., and Rozenfeld, H., "The deployment of product-related environmental legislation into product requirements," Sustainability 8(4), 332 (2016).

[12] Boks, C., and Diehl, J. C., "Ecobenchmarking for all," Proceedings of $4^{\text {th }}$ International Symposium on Environmentally Conscious Design and Inverse Manufacturing, pp. 792-798, Tokyo, Japan, December 12-14 (2005), <https://ieeexplore.ieee.org/document/1619352>.

[13] Vezzoli, C., and Manzini, E., [Design for Environmental Sustainability], Springer, London, United Kingdom (2008).

[14] Raudaskoski, A., Lenau, T. A., Jokinen, T., Gisslén, A. V., and Metze, A.-L., [Designing Plastics Circulation Electrical and Electronic Products], Nordic Council of Ministers, Copenhagen, Denmark (2019).

[15] Blomsma, F., Pieroni, M., Kravchenko, M., Pigosso, D. C. A., Hildenbrand, J., Kristinsdottir, A. R., Kristoffersen, E., Shabazi, S., Nielsen, K. D., Jönbrink, A.-K., Li, J., Wiik, C., and McAloone, T. C., "Developing a circular strategies framework for manufacturing companies to support circular economy-oriented innovation," Journal of Cleaner Production 241, 118271 (2019).

[16] de Pádua Pieroni, M., Blomsma, F., McAloone, T. C., and Pigosso, D. C. A., "Enabling circular strategies with different types of product/service-systems," Procedia CIRP 73, 179-184 (2018).

[17] European Union, "Regulation (EC) No. 1907/2006 - Registration, Evaluation, Authorisation and Restriction of Chemicals (REACH)]," 2006, <https://osha.europa.eu/en/legislation/directives/regulation-ec-no-1907-2006-ofthe-european-parliament-and-of-the-council> (29 March 2020).

[18] Yu, J., Welford, R., and Hills, P., "Industry responses to EU WEEE and ROHS directives: Perspectives from China," Corporate Social Responsibility and Environmental Management 13(5), 286-299 (2006).

[19] Bhamra, T., and Lofthouse, V., [Design for Sustainability: A Practical Approach], Routledge, Abingdon, Oxford, United Kingdom (2016).

[20] International Standards Organization, "ISO 14044:2006 Environmental Management - Life Cycle Assessment Requirements and Guidelines," 2006, <https://www.iso.org/standard/38498.html> (29 March 2020).

[21] International Standards Organization, "ISO 14044:2006 Environmental Management - Life Cycle Assessment Principles and Framework," 2006, <https://www.iso.org/standard/37456.html> (29 March 2020).

[22] Lenau, T. A., Metze, A.-L., and Hesselberg, T., "Paradigms for biologically inspired design," Proceedings of SPIE 10593, 1059302 (2018).

[23] International Standards Organization, "ISO 18458:2015 Biomimetics - Terminology, Concepts and Methodology," 2015, < https://www.iso.org/standard/62500.html> (29 March 2020).

[24] Lenau, T., "Biomimetics as a design methodology - Possibilities and challenges," Proceedings of the $17^{\text {th }}$ 
International Conference on Engineering Design, pp. 5-121-5-132, Stanford University, Stanford, CA, USA, August 24-27 (2009).

[25] Lenau, T., Orrù, A., and Linkola, L., [Biomimicry in the Nordic Countries], Nordic Council of Ministers, Copenhagen, Denmark (2018).

[26] Helms, M., Vattam, S. S., and Goel, A. K., "Biologically inspired design: process and products," Design Studies 30(5), 606-622 (2009).

[27] Lenau, T. A., Keshwani, S., Chakrabarti, A.., Ahmed-Kristensen, S., "Biocards and level of abstraction," Proceedings of the 20th International Conference on Engineering Design, pp. 177-186, Politecnico di Milano, Milan, Italy, July 27-30 (2015).

[28] Harrington, M. J., Masic, A., Holten-Andersen, N., Waite, J. H., and Fratzl, P., "Iron-clad fibers : A metal-based biological strategy for hard flexible coatings," Science 328(5975), 216-220 (2010).

[29] Holten-Andersen, N., Harrington, M. J., Birkedal, H., Lee, B. P., Messersmith, P. B., Lee, K. Y. C., and Waite, J. H., "pH-induced metal-ligand cross-links inspired by mussel yield self-healing polymer networks with nearcovalent elastic moduli," Proceedings of National Academy of Sciences USA 108(7), 2651-2655 (2011).

[30] Saito, A., Murase, J., Yonezawa, M., Watanabe, H., Shibuya, T., Sasaki, M., Ninomiya, T., Noguchi, S., Akaikasaya, M., and Kuwahara, Y., "High-throghput reproduction of the Morpho butterfly's specific high contrast blue," Proceedings of SPIE 8339, 83390C (2012).

[31] Chung, K., Yu, S., Heo, C.-J., Shim, J. W., Yang, S.-M., Han, M. G., Lee, H.-S., Jin, Y., Lee, S. Y., Park, N., and Shin, J. H., "Flexible, angle-independent, structural color reflectors inspired by Morpho butterfly wings," Advanced Materials 24(18), 2375-2379 (2012).

[32] Pulsifer, D. P., Lakhtakia, A., Narkhede, M. S.., Domingue, M. J., Post, B. G., Kumar, J., Martín-Palma, R. J., Baker, T. C., "Fabrication of polymeric visual decoys for the male emerald ash borer (Agrilus planipennis)," Journal of Bionic Engineering 10(2), 129-138 (2013).

[33] Gupta, T., Swiontek, S. E., Lakhtakia, A., "Simpler Mass Production of Polymeric Visual Decoys for the Male Emerald Ash Borer (Agrilus planipennis)," Journal of Bionic Engineering 12(2), 263-269 (2015).

[34] Tero, A., Takagi, S., Saigusa, T., Ito, K., Bebber, D. P., Fricker, M. D., Yumiki, K., Kobayashi, R., and Nakagaki, T., "Rules for biologically inspired adaptive network design," Science 327(5964), 439-442 (2010).

[35] Tero, A., Yumiki, K., Kobayashi, R., Saigusa, T., and Nakagaki, T., "Flow-network adaptation in Physarum amoebae," Theory in Biosciences 127(2), 89-94 (2008).

[36] Tero, A., Kobayashi, R., and Nakagaki, T., "A mathematical model for adaptive transport network in path finding by true slime mold," Journal of Theoretical Biology 244(4), 553-564 (2007).

[37] Seeley, T. D., Visscher, P. K., Schlegel, T., Hogan, P. M., Franks, N. R., and Marshall, J. A. R., "Stop signals provide cross inhibition in collective decision-making by honeybee swarms," Science 335(6064), 108-111 (2012).

[38] Seeley, T. D., [Honeybee Democracy], Princeton Univerity Press, Princeton, NJ, USA (2010).

[39] Gilbert, S., Lewis, L. A., and Schneider, S. S., "The role of the vibration signal during nest-site selection by honey bee swarms," Ethology 117(3), 254-264 (2011).

[40] Ball, P., "Shark skin and other solutions," Nature 400(6744), 507-509 (1999).

[41] Reynolds, C. W., "Flocks, herds, and schools: A distributed behavioral model," ACM Computer Graphics 21(4), 25-34 (1987).

[42] Ballerini, M., Cabibbo, N., Candelier, R., Cavagna, A., Cisbani, E., Giardina, I., Orlandi, A., Parisi, G., Procaccini, A., Viale, M., and Zdravkovic, V., "Empirical investigation of starling flocks: a benchmark study in collective animal behaviour," Animal Behavior 76(1), 201-215 (2008).

[43] Davenport, J., Hughes, R. N., Shorten, M., and Larsen, P. S., "Drag reduction by air release promotes fast ascent in jumping emperor penguins-a novel hypothesis," Marine Ecology Progress Series 430, 171-182 (2011).

[44] Lenau, T., and Hesselberg, T., "Biomimetic self-organization and self-healing," [Engineered Biomimicry], pp. 333-358, Elsevier, Waltham, MA, USA (2013). 